\title{
Desempenho de ovelhas nativas em confinamento recebendo palma-forrageira na dieta na região do semiárido nordestino ${ }^{1}$
}

\author{
Cicília Maria Silva de Souza ${ }^{2}$, Ariosvaldo Nunes de Medeiros ${ }^{3}$, Dermeval Araújo Furtado ${ }^{4}$ \\ Ângela Maria Vieira Batista ${ }^{5}$, Edgard Cavalcanti Pimenta Filho ${ }^{3}$, Divan Soares da Silva ${ }^{3}$ \\ 1 Pesquisa financiada pela CAPES/CNPq. \\ 2 Centro de Ciências Agrárias da Universidade Federal da Paraíba, CEP: 58397-000, Areia, PB, Brasil. \\ 3 Departamento de Zootecnia do Centro de Ciências Agrárias da Universidade Federal da Paraíba, CEP: 8397-000, Areia, PB, Brasil. \\ ${ }^{4}$ Departamento de Engenharia Agrícola da Universidade Federal de Campina Grande, CEP: 58109-970, Campina Grande, PB, Brasil. \\ ${ }^{5}$ Departamento de Zootecnia da Universidade Federal Rural de Pernambuco, CEP: 52171-030, Recife, PE, Brasil.
}

\begin{abstract}
RESUMO - O experimento foi conduzido com o objetivo de avaliar o ganho de peso, o consumo e a digestibilidade aparente dos nutrientes de dieta à base de palma forrageira em ovelhas nativas confinadas na região do semiárido nordestino. Foram testadas duas formas de oferecimento da palma-forrageira (Opuntia ficus-indica): separada da mistura feno de capim-tifton + concentrado e junto da mistura feno + concentrado. Utilizaram-se 40 fêmeas das raças nativas Barriga-preta, Cara-curta, Cariri e Morada Nova, com peso inicial médio de 36,76 kg, distribuídas em delineamento inteiramente casualizado, em arranjo fatorial $4 \times 2$, com quatro raças e duas estratégias de alimentação. Os genótipos e as estratégias de alimentação influenciaram os consumos médios de fibra em detergente neutro e nutrientes digestíveis totais e os coeficientes de digestibilidade aparente da fibra em detergente neutro. O genótipo influencia o ganho de peso e a conversão alimentar em ovelhas alimentadas com palma forrageira na dieta, uma vez que animais das raças Cariri e Cara-curta apresentam maiores ganhos de peso.
\end{abstract}

Palavras-chave: consumo, ganho de peso, manejo alimentar, ovino deslanado

\section{Performance of native ewes under feedlot system receiving spineless cactus in diet in Brazilian semiarid region}

\begin{abstract}
The experiment was carried out with the objective of evaluating the weight gain, intake of nutrients, and the apparent digestibility of diets based on spineless cactus in native ewes in feedlot system in Brazilian semiarid region. Two spineless cactus feeding strategies were evaluated: spineless cactus (Opuntia ficus-indica) separated from the Tifton hay + concentrated mixture, and with Tifton hay mixture + concentrate. It was used forty native breed ewes (Barriga Preta, Cara Curta, Cariri and Morada Nova), with average initial body weight of $36.76 \mathrm{~kg}$, distributed in a complete randomized design in a $4 \times 2$ factorial scheme (four breed and two feeding strategies). The genotypes and feeding strategies neutral fiber detergent had effect on the average intake of neutral fiber detergent and total digestible nutrient, and on the coefficients of neutral fiber detergent. Genotypes affect weight gain and food conversion in ewes fed spineless cactus diets since Cariri and Cara curta breeds show greater weight gain.
\end{abstract}

Key Words: intake, feeding management, sheep without fleece, weight gain

\section{Introdução}

A Região Nordeste possui um rebanho com de 8,7 milhões de ovinos que corresponde a $57,2 \%$ do efetivo nacional (IBGE, 2007). Esses animais caracterizam-se pela extrema capacidade de adaptação às diversas condições ambientais e suas populações são formadas principalmente por animais nativos e sem padrão racial definido, de notável rusticidade e produtividade (Oliveira et al., 2005).
Os ovinos nativos são naturalmente adaptados ao ambiente da região semi árida e estão bem ajustados aos sistemas de exploração extensivo e semi extensivo. Uma estratégia adotada para a melhoria do desempenho dos rebanhos nordestinos de pequenos ruminantes é a utilização de manejo alimentar adequado (Araujo Filho et al., 2010), com base nos sistemas intensivos de produção (confinamento ou semi-confinamento) durante as épocas de escassez alimentar, visando manter a regularidade na 
oferta de produtos no mercado (Cunha et al., 2009). Criados para produção de carne e pele, possuem excelentes prolificidade e habilidade materna; porém, existem poucas informações sobre esses animais e suas características alimentares e nutricionais.

Dentre estas características, o consumo voluntário é determinante no ingresso de nutrientes e na eficiência com que esses nutrientes são utilizados nos processos metabólicos do animal para atender as exigências de mantença e de produção. O consumo voluntário está associado ao coeficiente de digestibilidade aparente, que indica a quantidade percentual de cada nutriente do alimento que o animal tem condição de utilizar (Alves et al., 2003).

A estratégia de alimentação baseada em mistura completa, ingredientes separados ou em formas intermediárias, continua sendo objeto de pesquisa dos zootecnistas, tendo em vista a variabilidade dos alimentos disponíveis para a nutrição animal e a necessidade de determinar a melhor forma de fornecê-los (Pessoa et al., 2005), para máxima eficiência de utilização.

Embora uma das maneiras de se avaliar uma dieta seja fornecer ao animal ingredientes separados, possibilitando a sua seleção, Van Soest (1994) relata que a utilização de volumosos junto ao concentrado na forma de ração completa, tem sido difundida como estratégia de melhorar a ingestão e regular a composição da dieta. Desse modo, teoricamente, os animais podem consumir de forma equilibrada todos os nutrientes, atendendo seus requerimentos nutricionais e reduzindo o efeito da seletividade do animal.

O objetivo neste trabalho foi avaliar o desempenho, o consumo e a digestibilidade aparente de ovelhas nativas confinadas recebendo a palma-forrageira na dieta, na região do semiárido nordestino.

\section{Material e Métodos}

O experimento foi conduzido na Unidade de Pesquisa em Pequenos Ruminantes, do Departamento de Zootecnia, do Centro de Ciências Agrárias da UFPB, localizada no município de São João do Cariri, Paraíba e teve duração de 64 dias: 18 dias de adaptação e 46 dias para a coleta de dados, ocorridos entre 20 de março a 22 de maio de 2005. A precipitação média nos meses do experimento foi de 95 mm e as temperaturas médias das máximas e das mínimas foram de 33 e $20,8^{\circ} \mathrm{C}$, respectivamente.

Foram utilizadas 40 ovelhas adultas, de quatro grupos genéticos nativos: Cariri, Barriga-preta, Cara-curta e Morada Nova, com pesos médios iniciais de 37,23; 40,57; 35,88 e 33,29 , respectivamente. As ovelhas foram everminadas e distribuídas aleatoriamente por genótipo e alojadas em quatro galpões com baias individuais, com $3,75 \mathrm{~m}^{2}$ de área, cobertas com telhas cerâmicas, piso de chão batido, providas de comedouro e bebedouro. Em cada galpão foi colocado um termohigrômetro, onde foi coletada a temperatura do bulbo seco e bulbo úmido, a cada duas horas, das 8 às 18 $\mathrm{h}$, e posteriormente calculada a umidade relativa do ar.

A dieta fornecida aos animais era composta depalma forrageira (Opuntia-fícus indica), feno de tifton (Cynodon dactylon L.) e concentrado à base de farelo de milho, farelo de soja, farelo de algodão e suplemento mineral. O feno de tifton foi moído em máquina tipo DMP (desintegrador, moedor e picador) utilizando-se peneira de $10 \mathrm{~mm}$, e misturado aos outros ingredientes da ração experimental, e a palma foi passada em picadeira.

A dieta foi formulada com base no NRC (1985) para atender às exigências de ovelhas em produção com peso vivo de $50 \mathrm{~kg}$ (Tabelas 1 e 2), com um ganho de peso, consumo de matéria seca e proteína bruta de 0,$100 ; 1,6$ e $0,150 \mathrm{~kg} /$ dia, respectivamente.

Tabela 1 - Composição nutricional dos ingredientes da dieta com base na matéria seca (\%)

\begin{tabular}{|c|c|c|c|c|c|c|}
\hline Nutriente & $\begin{array}{l}\text { Farelo de } \\
\text { milho }\end{array}$ & $\begin{array}{l}\text { Farelo de } \\
\text { soja }\end{array}$ & $\begin{array}{l}\text { Farelo de } \\
\text { algodão }\end{array}$ & $\begin{array}{l}\text { Suplemento } \\
\text { mineral }\end{array}$ & $\begin{array}{l}\text { Palma } \\
\text { forrageira }\end{array}$ & $\begin{array}{c}\text { Feno de } \\
\text { capim-tifton }\end{array}$ \\
\hline Matéria seca & 84,5 & 84,8 & 83,4 & 97,1 & 10,0 & 90,0 \\
\hline Matéria orgânica & 96,37 & 93,42 & 95,16 & - & 85,78 & 93,29 \\
\hline Matéria mineral & 3,63 & 6,58 & 4,84 & 86,08 & 14,22 & 6,71 \\
\hline Proteína bruta & 11,4 & 46,9 & 25,0 & - & 3,0 & 7,0 \\
\hline $\begin{array}{l}\text { Fibra em detergente neutro corrigida } \\
\text { para cinzas e proteína }\end{array}$ & 37,11 & 16,55 & 63,18 & - & 26,0 & 70,0 \\
\hline Fibra em detergente ácido & 5,96 & 9,24 & 37,23 & - & 20,0 & 45,0 \\
\hline Extrato etéreo & 11,49 & 2,13 & 1,72 & - & 0,5 & 1,5 \\
\hline Carboidratos totais & 73,54 & 44,35 & 64,60 & - & 82,53 & 83,62 \\
\hline Carboidratos não-fibrosos & 17,06 & 4,53 & 1,43 & - & 27,87 & 4,13 \\
\hline
\end{tabular}

${ }^{1}$ Subproduto da fabricação de flocos de milho. 
Tabela 2 - Composição da dieta, com base na matéria seca

\begin{tabular}{lr}
\hline Ingrediente & $(\%)$ \\
\hline Farelo de soja & 16,45 \\
Farelo de milho $^{1}$ & 16,24 \\
Farelo de algodão $^{2}$ & 15,06 \\
Suplemento mineral $^{2}$ & 2,25 \\
Feno de capim-tifton & 40,0 \\
Palma forrageira & 10,0 \\
Composição química (\%) & $(\%)$ \\
Matéria seca & 49,13 \\
Matéria orgânica & 91,56 \\
Matéria mineral & 8,44 \\
Proteína bruta & 16,43 \\
Extrato etéreo & 2,47 \\
Carboidratos totais & 70,66 \\
Carboidratos não-fibrosos & 8,17 \\
Fibra em detergente neutro corrigida & \\
para cinzas e proteína & 48,86 \\
Fibra em detergente ácido & 28,09 \\
\hline
\end{tabular}

${ }^{1}$ Subproduto da fabricação de flocos de milho.

${ }^{2}$ Suplemento mineral: $\mathrm{Zn}-1.600 \mathrm{mg} ; \mathrm{Cu}-600 \mathrm{mg}$; Mn - $1.500 \mathrm{mg} ; \mathrm{Fe}-1.100 \mathrm{mg}$; Co - 10 mg; I - 27 mg; e Se - 22 mg. Veículo q.s.p. - 1.000 g.

O arraçoamento dos animais foi realizado duas vezes ao dia, às $7 \mathrm{~h}$ e às $15 \mathrm{~h}$. A relação volumoso:concentrado utilizada foi de 50:50, considerando a palma e o feno como volumosos. A quantidade de ração fornecida diariamente foi ajustada de acordo com o consumo do dia anterior de modo que as sobras correspondessem a $20 \%$ da matéria natural do total fornecido a fim de proporcionar ingestão à vontade. As estratégias de alimentação utilizadas foram: ingredientes separados = palma forrageira separada da mistura feno + concentrado; e mistura completa $=$ palma misturada com o concentrado e o feno. Para estimativa dos consumos dos nutrientes de matéria seca, matéria orgânica, matéria mineral, proteína bruta, fibra em detergente neutro, fibra em detergente ácido, carboidratos totais, extrato etéreo e nutrientes digestíveis totais, a quantidade de ração oferecida foi pesada e registrada, assim como as sobras.

As sobras de cada baia foram pesadas e amostradas diariamente e armazenada em congelador para formação de uma única amostra. Também foi feita coleta do material oferecido a cada 15 dias e as amostras foram conservadas a $-10^{\circ} \mathrm{C}$, para posterior determinação dos teores de nutrientes de acordo com a metodologia descrita por Silva \& Queiroz (2002). As análises foram realizadas no Laboratório de Nutrição Animal e Avaliação de Alimentos do CCA/UFPB.

Para a determinação do ganho de peso total e diário, as ovelhas foram pesadas semanalmente e, para a conversão alimentar, considerou-se a ingestão de MS em kg/dia dividida pelo ganho de peso médio diário.

As análises de matéria seca, matéria orgânica, proteína bruta, extrato etéreo e matéria mineral foram realizadas de acordo com a metodologia de Silva \& Queiroz (2002); fibra em detergente neutro e fibra em detergente ácido foram determinadas utilizando-se o aparelho Ankom ${ }^{200}$, da Ankom Technology Corporation, de acordo com o método de Van Soest (1991) utilizando-se sacos de TNT (tecidonão-tecido) gramatura $100 \mathrm{~mm}$, confeccionados no Laboratório de Nutrição Animal.

Para estimativa dos carboidratos totais, utilizou-se a seguinte equação propostas por Sniffen et al. (1992), $\mathrm{CT}(\%)=100-(\% \mathrm{~PB}+\% \mathrm{EE}+\%$ Cinzas $)$. Os carboidratos não- fibrosos (CNF) e os nutrientes digestíveis totais (NDT) foram calculados de acordo com Weiss (1999) como: CNF $(\%)=100-(\% \mathrm{FDN}+\% \mathrm{~PB}+\% \mathrm{EE}+\%$ Cinzas $) ; \mathrm{NDT}=\mathrm{PBD}$ $+\mathrm{EED} * 2,25+\mathrm{CNFD}+\mathrm{FDNcpD}$, em que $\mathrm{PBD}=(\mathrm{PB}$ ingerida - $\mathrm{PB}$ fezes $), \mathrm{EED}=(\mathrm{EE}$ ingerido $-\mathrm{EE}$ fezes $), \mathrm{CNFD}=(\mathrm{CNF}$ ingeridos - CNF fezes $)$ e FDNCPD $=($ FDNCP ingerido FDNCP fezes $)$; e a $\%$ NDT $=\left(\mathrm{CNDT}^{*} 100\right) / \mathrm{CMS} \mathrm{kg} / \mathrm{dia}$.

A composição da dieta efetivamente consumida pelos animais foi calculada dividindo-se o consumo voluntário de cada nutriente da dieta pela MS consumida e multiplicando-se por 100. Para avaliar o ganho de peso total, diário e metabólico, as pesagens foram feitas no início de cada semana do período experimental, ou seja, a cada sete dias.

Para determinação dos coeficientes de digestibilidade da matéria seca, matéria orgânica, proteína bruta, extrato etéreo, fibra em detergente neutro, fibra em detergente ácido e carboidratos totais, foram feitas coletas de fezes dos animais, realizadas diretamente da porção final do reto, sempre após a alimentação, durante cinco dias. As amostras de fezes foram armazenadas a $-10^{\circ} \mathrm{C}$ e posteriormente, da mesma forma que os alimentos e sobras, foram processadas ao término do período experimental, quando então o material colhido foi descongelado e homogeneizado e as amostras foram compostas por animal, secas em estufa com ventilação forçada a $55^{\circ} \mathrm{C}$ por 72 horas e moídas.

A estimativa da produção fecal foi feitada utilizando-se a fibra em detergente ácido indigestível (FDAi) como indicador interno. As amostras de fezes, alimentos e sobras foram incubadas in vitro em sacos de tecido com gramatura de $100 \mathrm{~mm}$, por um período de 144 horas segundo metodologia descrita por Berchielli et al. (2000). A quantidade da amostra incubada foi de $1 \mathrm{~g}$ para alimentos, sobras e fezes. O material remanescente da incubação foi submetido à extração com detergente ácido e o resíduo foi considerado FDAi. O cálculo da matéria seca fecal (MSF) em quilogramas $(\mathrm{kg})$ é a razão entre o indicador consumido $(\mathrm{kg})$ pela porcentagem do indicador nas fezes multiplicado por 100 . 
O coeficiente de digestibilidade aparente (CDA) foi calculado a partir da diferença entre o consumo de nutrientes $(\mathrm{kg})$ pelo nutriente excretado nas fezes $(\mathrm{kg})$, dividido pelo consumo de nutrientes $(\mathrm{kg})$ e multiplicado por 100.

$\mathrm{Na}$ análise estatística, foi feita a comparação entre genótipos e estratégia alimentar, utilizando-se um delineamento estatístico inteiramente casualizado com arranjo fatorial $4 \times 2$, (composto de quatro genótipos e duas estratégias alimentares), com cinco repetições, em que as fontes de variação foram genótipos, estratégia alimentar e a interação genótipo $\times$ estratégia alimentar. $\mathrm{O}$ modelo estatístico adotado foi: $\mathrm{Y}_{\mathrm{ijk}}=\mu+\mathrm{G}_{\mathrm{i}}+\mathrm{EA}_{\mathrm{j}}+\mathrm{G}^{*} \mathrm{EA}_{\mathrm{ij}}+\mathrm{e}_{\mathrm{ijk}}$, em que: $Y_{i j k}=$ observação realizada; $\mu=$ média; $G=$ efeito do genótipo $(\mathrm{n}=4) ; \mathrm{EA}=$ efeito da estratégia alimentar $(n=2) ; G^{*} E A_{i j}=$ interação genótipo $\times$ estratégia alimentar; $\mathrm{i}=$ estratégia alimentar mistura completa; $\mathrm{j}=$ estratégia alimentar de ingredientes separados; e $\mathrm{E}_{\mathrm{ijk}}=$ erro aleatório associado a cada observação. Os dados foram avaliados por meio de análise de variância adotando-se o teste $\mathrm{F}$ e o teste Tukey a $5 \%$ de probabilidade, pelo programa estatístico SAEG 5.0.

\section{Resultados e Discussão}

Os consumos de nutrientes, exceto FDN $(\mathrm{P}<0,05)$ e NDT $(\mathrm{P}<0,01)$, não diferiram entre os genótipos, independentemente da forma expressa (Tabela 3 ), o que pode ser atribuído à semelhança genética e morfofisiológica na formação dos grupos genéticos, provavelmente originados de troncos comuns, apesar de suas características fenotípicas serem diferentes, em razão da pressão de seleção natural a que foram submetidas ao longo de sua formação. Além disso, as ovelhas estavam nas mesmas condições ambientais, cuja temperatura média nas instalações foi de $27,8^{\circ} \mathrm{C}$ e a umidade relativa do ar de $67,5 \%$, encontrando-se dentro da zona de conforto térmico da espécie (Silva, 2000).

O consumo dos nutrientes avaliados diferiu entre as estratégias de alimentação diferentes, com exceção apenas da matéria orgânica, da matéria mineral, do extrato etéreo e dos carboidratos totais. Já a interação entre genótipo e estratégia alimentar $(\mathrm{G} \times \mathrm{EA})$ foi observada para os consumos de fibra em detergente ácido, fibra em detergente neutro, carboidratos não-fibrosos e nutrientes digestíveis totais, de modo que o desdobramento da interação mostra maiores valores para os animais submetidos à estratégia alimentar mistura completa.

$\mathrm{O}$ fato de os consumos de matéria seca, fibra em detergente neutro e fibra em detergente ácido terem sido maiores nos animais que receberam mistura completa pode ser justificado pela aderência do feno e do concentrado à palma no ato da homogeneização da ração, possibilitando maior ingestão de feno, que possui elevado teor de constituintes da parede celular. Os animais que receberam os ingredientes da dieta de forma separada ingeriram inicialmente a palma e posteriormente consumiram a mistura de feno e concentrado permitindo comprovar visualmente que os animais submetidos a esta estratégia de alimentação apresentavam comportamento seletivo para esta mistura, aumentando as sobras de feno e contribuindo para o desbalanceamento da dieta ingerida. Estes resultados estão relacionados às diferenças no consumo dos ingredientes da dieta, resultante da preferência alimentar, da capacidade de ingestão e de sua apresentação aos animais, seja na forma de mistura completa seja em ingredientes separados (Ostergaard et al., 2000).

$\mathrm{O}$ desdobramento por meio da interação $(\mathrm{G} \times \mathrm{EA})$ apresentada pelo consumo de carboidratos não-fibrosos comprova maiores resultados para a estratégia alimentar com os ingredientes separados, situação que pode ser justificada pelo menor consumo de fibra em detergente neutro e ácido quantificada pela mesma estratégia alimentar.

A raça Barriga-Preta apresentou maior consumo de carboidratos não-fibrosos, com consumo de $0,90 \mathrm{~kg} / \mathrm{dia}$, e este fato pode ter decorrido de sua maior estatura física e da possível descendência com animais mestiços de Santa Inês. Já os genótipos Cariri, Morada Nova e Cara Curta apresentaram os menores consumos de carboidrato nãofibrosos, fato relacionado ao menor tamanho corporal e à menor capacidade física em distender o rúmen. Essas características estão ligadas diretamente ao fator animal (grupo genético), influenciando seu consumo voluntário.

Pessoa et al. (2004) investigaram os efeitos de diferentes estratégias alimentares (IS e MC) em dietas à base de palma forrageira sobre o desempenho de vacas leiteiras e observaram que não houve diferenças nos consumos de matéria seca, matéria orgânica, extrato etéreo e proteína bruta, onde concluíram que a estratégia alimentar com ingredientes separados contribui para o desbalanceamento da dieta, afetando a produtividade animal.

Houve efeito dos genótipos $(\mathrm{P}<0,01)$ no percentual de carboidratos totais efetivamente consumido, além da interação entre $\mathrm{G} \times \mathrm{EA}$, que foi mais elevado para a estratégia alimentar mistura completa (Tabela 4). Normalmente, o valor nutritivo da dieta ingerida pelos animais é diferente daquele que foi ofertado.

Quando as ovelhas receberam os ingredientes na forma separada, o consumo efetivo de matéria seca foi inferior ao fornecido na dieta $(49,13 \%$ - Tabela 2). Por outro lado, 

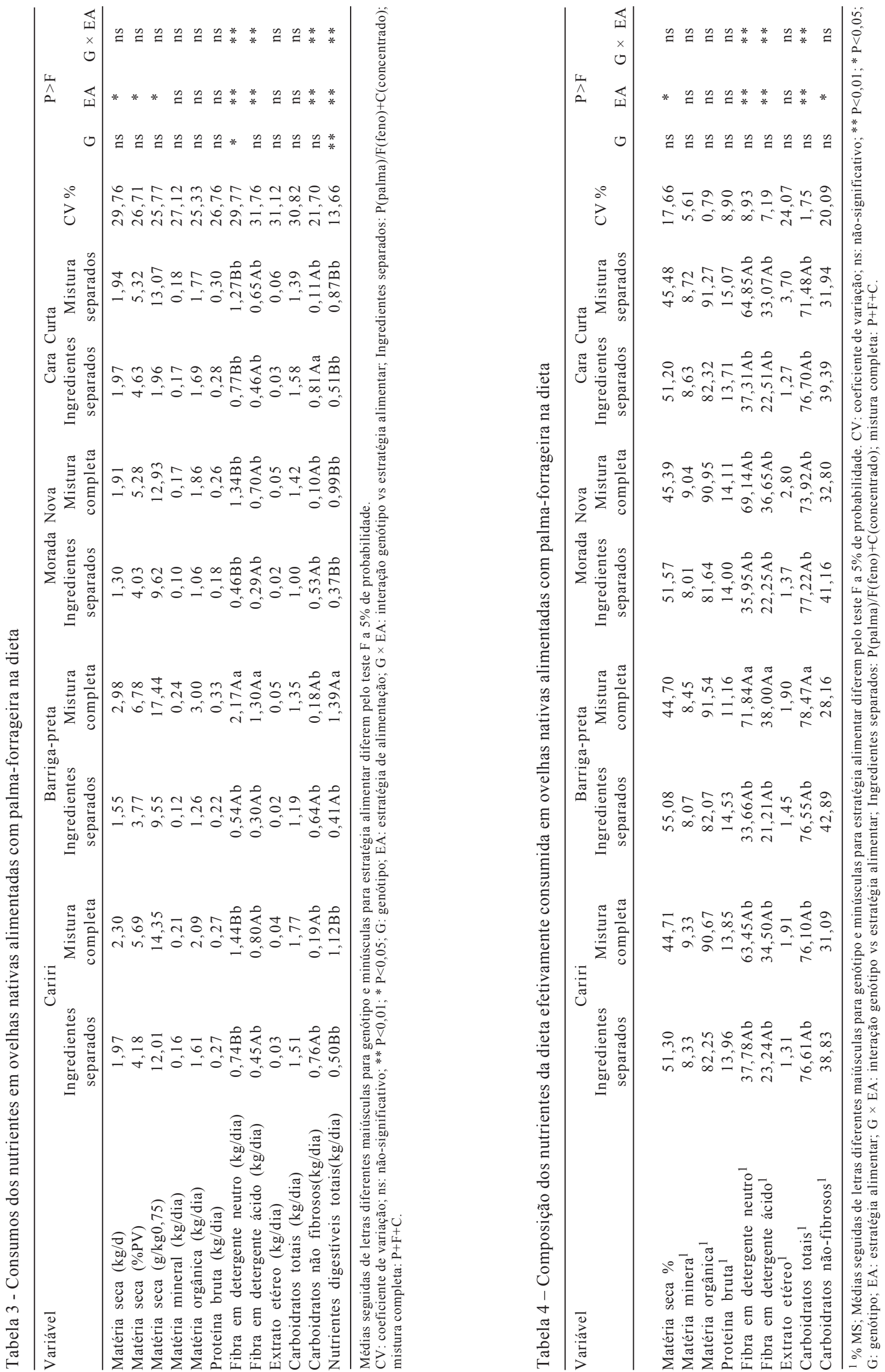

R. Bras. Zootec., v.39, n.5, p.1146-1153, 2010 
quando receberam a dieta na forma completa, o consumo efetivo da MS foi superior ao da dieta ofertada.

O percentual de fibra em detergente neutro e de fibra em detergente ácido efetivamente consumido dos ingredientes separados foi superior ao da dieta ofertada $(48,86$ e $28,09 \%$, respectivamente) as ovelhas alimentadas com a mistura completa. O elevado teor de fibra da dieta e a aderência da palma forrageira ao feno e ao concentrado dificultaram a seleção dos ingredientes, o que explicaria a influência da estratégia alimentar sobre o consumo efetivo de fibra.

$\mathrm{O}$ fato de os animais submetidos à estratégia alimentar com ingredientes separados selecionarem e consumirem prioritariamente a palma e o concentrado (ambos os ingredientes ricos em carboidratos não-fibrosos) e só posteriormente o feno promoveu maior consumo efetivo dos carboidratos totais e não-fibrosos.

Os respectivos coeficientes de variação e as médias de digestibilidade da matéria seca, matéria orgânica, proteína bruta, fibra em detergente neutro, fibra em detergente ácido, extrato etéreo, carboidratos totais e nutrientes digestíveis totais não diferiram entre os genótipos $(\mathrm{P}>0,05)$ nem apresentou interação $(\mathrm{G} \times \mathrm{EA})$, exceto para a digestibilidade aparente da fibra em detergente neutro (Tabela 5).

O desdobramento ocorrido a partir da interação $(\mathrm{G} \times \mathrm{EA})$ apresentada pela digestibilidade da fibra em detergente neutro comprovou efeito significativo $(\mathrm{P}<0,001)$ para a estratégia alimentar ingredientes separados, com resultado inferior ao obtido com a mistura completaem decorrência do maior consumo da mistura feno e concentrado em relação à palma.

Nos genótipos nativos Cariri (49,63\%), Morada Nova $(54,84 \%)$ e Cara-curta $(52,31 \%)$ a digestibilidade da fibra em detergente neutro foi semelhante e superior à observada no genótipo Barriga-preta $(48,36 \%)$, fato atribuído à rápida taxa de passagem do alimento pelo trato gastrintestinal, que promoveu elevado consumo de fibra em detergente neutro nos genótipos Cariri (1,09\%), Morada Nova ( $0,90 \%)$ e Cara-curta $(1,02)$.

O fato de a digestibilidade aparente da matéria seca, fibra em detergente neutro e fibra em detergente ácido obtida com o fornecimento dos ingredientes separados ter sido superior à da mistura completa e a digestibilidade da proteína bruta ter sido inferior pode ser explicado pela maior ingestão dos carboidratos não-fibrosos, cuja digestibilidade é superior a $90 \%$, e pela menor ingestão dos carboidratos estruturais, que apresentam digestibilidade próxima a $50 \%$.

Estes resultados diferem dos encontrados por Silva et al. (2005) que estudaram o efeito de estratégias alimentares com dietas à base de palma forrageira sobre a digestibilidade

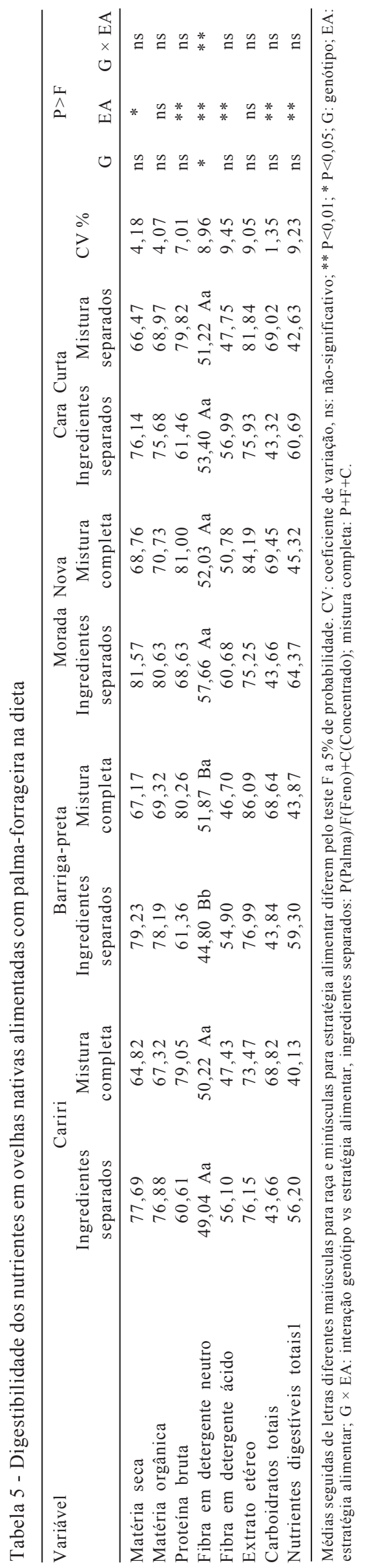

R. Bras. Zootec., v.39, n.5, p.1146-1153, 2010 
em vacas em final de lactação e não observaram diferenças significativas na digestibilidade dos nutrientes.

O valor obtido neste estudo para o coeficiente de digestibilidade aparente da proteína bruta quando as ovelhas foram submetidas à estratégia alimentar mistura completa foi superior aos encontrados por Silva et al. (2005), para o mesmo parâmetro em animais submetidos à estratégia alimentar com mistura completa à base de palma forrageira, cujo resultado foi de $70 \%$.

O percentual de nutrientes digestíveis totais obtidos para a estratégia alimentar em ingredientes separados foi superior ao da mistura completa, em razão do comportamento seletivo das ovelhas que ingeriram rapidamente quantidade representativa de palma e só posteriormente ingerirem o feno juntamente com o concentrado.

Pessoa et al. (2005), avaliaram diferentes estratégias alimentares à base de palma e silagem de sorgo e não observaram influência nos coeficientes de digestibilidade dos nutrientes.

$\mathrm{O}$ genótipo teve efeito $(\mathrm{P}<0,05)$ sobre o peso médio inicial e final e o ganho de peso total, diário e metabólico, com exceção apenas da conversão alimentar (Tabela 6). O desempenho não sofreu influência $(\mathrm{P}>0,05)$ das estratégias alimentares.

Entre os grupos genéticos estudados, o Cariri e o CaraCurta tiveram desempenhos superiores, com ganhos totais de 4,49 $\mathrm{kg}$ e $3,16 \mathrm{~kg}$, respectivamente. Este fato pode estar relacionado ao processo de formação das raças, tanto de suas origens quanto do tempo sob seleção natural, onde normalmente uma população em que os aspectos de sobrevivência e reprodução foram mais destacados, levando os animais a um crescimento mais acelerado. Dessa forma, os grupos genéticos Cariri e Cara-Curta, considerados genótipos de grande porte, necessitam de maior demanda de nutrientes, resultando em maiores ganhos.

Apesar da anatomia mandibular diferenciada, o grupo genéticoCara-Curta apresentou aparelho bucal menor e mais curto,com consumo semelhante ao dos grupos genéticos Cariri, Barriga-Preta e Morada Nova, mantendo seu desempenho, com ganho de peso total, diário e peso metabólico de 3,16 kg; 0,052 g/dia e 15,54 $\mathrm{PV}^{0,75}$, respectivamente. Esse resultado pode ser atribuído à ingestão de matéria seca, de $1,97 \mathrm{~kg} / \mathrm{dia}$ quando os ingredientes estavam separados, e de 1,94 kg/dia quando fornecida mistura completa.

Apesar de não ter apresentado diferenças estatísticas $(\mathrm{P}>0,05)$, a conversão alimentar apresentou valores elevados e um alto coeficiente de variação $\mathrm{CV}=77,53 \%$ (Tabela 6), resultado diretamente relacionado ao elevado consumo de MS e ao baixo ganho de peso dos animais, já

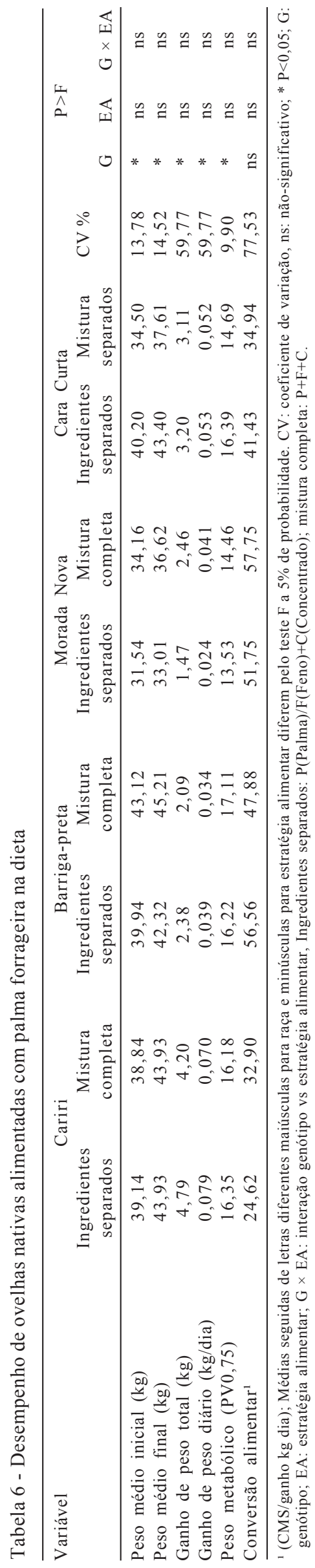

R. Bras. Zootec., v.39, n.5, p.1146-1153, 2010 
que as ovelhas eram adultas e pesavam inicialmente $36,70 \mathrm{~kg}$ de PV, e já haviam superado a fase de crescimento.

\section{Conclusões}

O genótipo de ovelhas nativas influencia positivamente o consumo e a digestibilidade da fibra em detergente neutro, refletindo no seu desempenho. A estratégia alimentar de misturar a palma aos demais ingredientes da dieta melhora o consumo de fibra, aumentando o consumo efetivo dos nutrientes.

\section{Agradecimentos}

À Coordenação de Aperfeiçoamento de Pessoal de Nível Superior - Capes, pela concessão da bolsa de estudos e financiamento do projeto, à Universidade Federal da Paraíba e ao Programa de Pós Graduação em Zootecnia, pelo apoio à realização deste trabalho. Aos alunos de pósgraduação e graduação que contribuíram na execução desta pesquisa.

\section{Referências}

ALVES, K.S.; CARVALHO, F.F.R.; FERREIRA, M.A. et al. Níveis de energia em dietas para ovinos Santa Inês: digestibilidade aparente. Revista Brasileira de Zootecnia, v.32, n.6, p.19621968,2003

ARAujo Filho, J.T.; COSTA, R.G.; FRAGA, A.B. et al. Desempenho e composição da carcaça de cordeiros deslanados terminados em confinamento com diferentes dietas. Revista Brasileira de Zootecnia, v.39, n.2, p.363-371, 2010.

BERCHIELli, T.T.; ANDRADE, P.; FURLAN, C.L. Avaliação de indicadores internos em ensaios de digestibilidade. Revista Brasileira de Zootecnia, v.29, n.3, p.830-833, 2000.

CUNHA, M.G.G.; CARVAlHO, F.F.R.; VÉRAS, S.C. et al. Desempenho e digestibilidade aparente em ovinos confinados alimentados com dietas contendo níveis crescentes de caroço de algodão integral. Revista Brasileira de Zootecnia, v.37, n.6, p.1103-1111, 2008 .

INSTITUTO BRASILEIRO DE GEOGRAFIA E ESTATÍSTICAS IBGE. [2007]. Sistema IBGE de recuperação automática. Disponível em: <http://www.ibge.gov.br/>. Acesso em: 4/3/2007.

NATIONAL RESEARCH COUNCIL - NRC. Nutrient requirements of sheep. 6.rev.ed. Washington, D.C.: National Academy of Science, 1985. 99p.

OLIVEIRA, F.M.M.; DANTAS, R.T.; FURTADO, D.A. et al. Parâmetros de conforto térmico e físiológico de ovinos Santa Inês, sob diferentes sistemas de acondicionamento. Revista Brasileira de Engenharia Agrícola e Ambiental, v.9, n.4, p.631-635, 2005.

OSTERGAARD, S.; GRÖHN, Y.T. Concentrate feeding, dry-matter intake, and metabolic disorders in Danish dairy cows. Livestock Production Science, v.65, n.1, p.107-118, 2000

PESSOA, R.A.S.; FERREIRA, M.A.; LIMA, L.E.A. et al. Desempenho de vacas leiteiras submetidas a diferentes estratégias alimentares. Archivos de Zootecnia, v.53, n.203, p.309-320. 2004.

PESSOA, R.A.S.; FERREIRA, M.A.; LIMA, L.E.A. et al. Vacas leiteiras submetidas a diferentes estratégias alimentares. Digestibilidade e balanço de energia. Acta Scientiarum. Animal Sciences, v.27, n.2, p.253-260, 2005.

SNIFFEN, C.; O'CONNOR, J.D.; VAN SOEST, P.J. et al. A net carbohydrate and protein system for evaluating cattle diets: II Carbohydrate and protein availability. Animal Science Journal, v.70, n.12, p.3562-3577, 1992.

SILVA, D.J.; QUEIROZ, A.C. Análise de alimentos: métodos químicos e biológicos. Viçosa, MG: UFV, 2002. 235p.

SILVA, R.G. Introdução à bioclimatologia animal. São Paulo: Nobel, 2000. 286p.

SILVA, A.E.V.N.; GUIM, A.; FERREIRA, M.A. et al. Estratégia Alimentar para dieta baseada em palma forrageira sobre o desempeno e digestibilidade em vacas em final de lactação. Acta Scientiarum. Animal Sciences, v.27, n.2, p.269-276, 2005.

VAN SOEST, P.J.; ROBERTSON, J.B.; LEWIS, B.A. Methods for extraction fiber, neutral detergent fiber and nonstarch polysaccarides in relation for animal nutrition. Journal of Dairy Science, v.83, n.1, p.3583-3597, 1991.

VAN SOEST, P.J. Nutrition ecology of the ruminant. 2.ed Ilhaca: Cornell University Press, 1994. 476p.

WEISS, W.P. Energy prediction equations for ruminant feeds. In: CORNELL NUTRITION CONFERENCE FOR FEED MANUfaCturers, 61., 1999, Ithaca. Proceedings... Ithaca: Cornell University, 1999. p.176-185. 